\author{
ARTICULO \\ Revista Derecho - Año 3 edicion 521 - 44
}

Web: http://revistas.unap.edu.pe/rd E-mail.com: revistaderecho@unap.edu.pe ISSN 2313-6944

\title{
LOS FUNDAMENTOS FILOSÓFICOS Y JURÍDICOS QUE JUSTIFICAN EL RECONOCIMIENTO DE LA MADRE TIERRA COMO SUJETO DE DERECHO
}

Juan Casazola Crama *

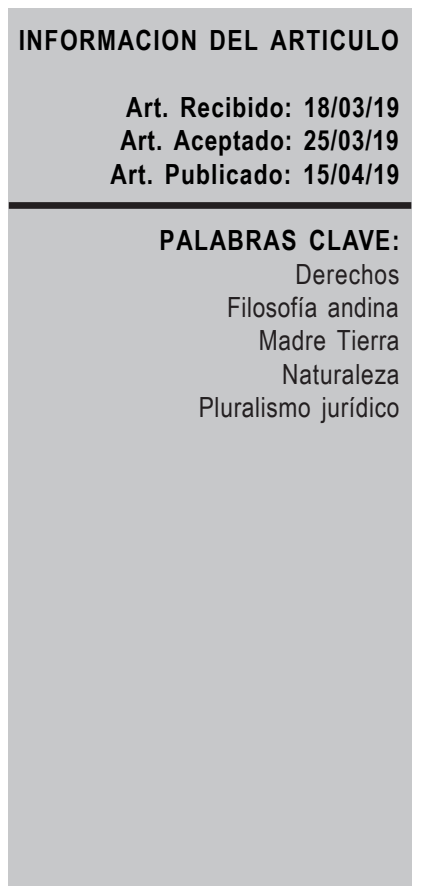

RESUMEN
Este trabajo desarrolla los fundamentos filosóficos y jurídicos para adjudicar y reconocer derechos a la Madre Tierra, concretamente, se plantea la necesidad de que la Madre Tierra sea reconocida como sujeto de derechos, sin embargo, al respecto, existen algunas dudas sobre su viabilidad y, especialmente, sobre los fundamentos que la avalan, por esa razón, el objetivo de la investigación fue establecer las posturas o corrientes- filosóficas y jurídicas que fundamentan el reconocimiento de la Madre Tierra como sujeto de derechos. Los métodos empleados fueron el análisis documental y hermenéutico, a su vez, la técnica usada fue la observación-directa que consistió en analizar la bibliografía pertinente al tema de estudio. Finalmente, los resultados a los que se han arribado son: (i) las posturas filosóficas como filosofía de la liberación y la filosofía andina, y, (ii) las posturas jurídicas como el derecho indígena y el pluralismo jurídico, en ambos casos, fundamentan y justifican el reconocimiento de derechos a la naturaleza, a su vez, promueven el tránsito del antropocentrismo-centralidad del hombre y su dignidad- hacia el biocentrismo - centralidad de la vida y el respeto de la diversidad de especies-. Con lo cual queda expuesta la presencia de fundamentación filosófica y jurídica para el reconocimiento de la madre tierra como sujeto de derechos.

Casazolajuan@hotmail.com

Docente de la Escuela Profesional de Derecho de la Universidad Nacional del Altiplano-Puno. 


\section{THE PHILOSOPHICAL AND LEGAL FOUNDATIONS THAT JUSTIFY THE RECOGNITION OF MOTHER EARTH AS A SUBJECT OF LAW}

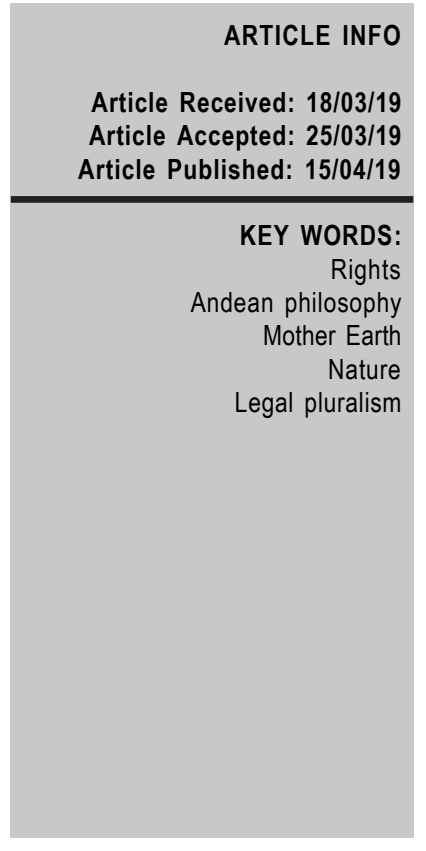

\begin{abstract}
This work develops the philosophical and legal foundations to assign and recognize rights to Mother Earth, specifically, the need for Mother Earth to be recognized as a subject of rights is raised, however, in this regard, there are some doubts about its viability and, especially, on the foundations that endorse, for that reason, the objective of the investigation was to establish the philosophical and legal positions or currents - that support the recognition of Mother Earth as a subject of rights. The methods used were the documentary and hermeneutical analysis, in turn, the technique used was direct observation that consisted of analyzing the bibliography relevant to the subject of study. Finally, the results to which they have arrived are: (i) the positions philosophical as philosophy of liberation and Andean philosophy, and, (ii) legal positions such as indigenous law and legal pluralism, in both cases, support and justify the recognition of rights to nature, in turn, promote the transit from anthropocentrism - centrality of man and his dignity - towards biocentrism - centrality of life and respect for the diversity of species-. With which the presence of philosophical and legal foundation for the recognition of the pachamama as a subject of rights is exposed.
\end{abstract}




\section{INTRODUCCIÓN}

En la actualidad la crisis ambiental viene consumiendo considerables espacios de la tierra, en especial, los pequeños ecosistemas donde se aloja la vida -lugar en la cual se desarrollan diversas especies-. La intervención del hombre en la naturaleza trae serias consecuencias en el medio ambiente -que habitualmente no son positivas-, especialmente, cuando se trata de realizar actividades extractivas porque al término de la misma gran parcela del ecosistema queda dañada y, en algunos casos, se destruye. Un hecho patente es que la humanidad viene produciendo una crisis ambiental sin precedentes porque la naturaleza progresivamente viene desagradándose - por la constante y progresiva invasión del hombre sobre la naturaleza-. En los últimos años, ha venido incrementándose exponencialmente la extracción de recursos naturales a través de las actividades como son la minería, la tala de bosques, obtención del crudo, entre otros, los mismos que tienen impactos negativos y profundizan mucho más la degradación ambiental, ello se produce por la ausencia de planes de desarrollo sostenibles y equilibrados -especialmente, cuando las actividades extractivas no son amigables con el ecosistema-.

En torno a la problemática ambiental se puede apreciar que en los últimos años se torna más visible e, inclu- sive, existen políticas y planes impulsados desde el poder público en este caso el Estado- para mitigar los impactos de las diversas actividades extractivas a las que se dedica el ser humano, a su vez, desde el plano individual, las personas van asumiendo como una tarea esencial proteger el medio ambiente porque es un lugar esencial para el desarrollo de la vida. En tal sentido, en términos generales podemos indicar que frente a la depredación ambiental vienen impulsándose múltiples estrategias para mitigar y disolver dicha problemática desde diversos sectores como son los activistas ambientales, el Estado a través de la elaboración de políticas ambientales sostenibles, la ciudadanía, la iglesia $-\mathrm{O}$ desde la fe-, movimientos indígenas por la defensa de la naturaleza, entre otros. Con todas estas acciones, la intención común es proteger y salvar a la Madre Tierra de su extinción o desaparición, a su vez, encontrar soluciones para revertir el daño ambiental que hasta el momento se ha ocasionado, por lo tanto, es una apuesta por la vida más allá de la economía, la industria, el crecimiento de capitales, la creación de empresas u otros, ya que ninguna forma de vida será posible si se pierde el único lugar donde la vida se desarrolla armoniosamente: la Madre Tierra, pachamama, naturaleza, planeta tierra, entre otros.

Con la finalidad de abordar la problemática ambiental desde diversas aristas y ópticas, en especial, para encon-

Revista Derecho - 5 (2019) 23 
trar soluciones y respuestas que sean compatibles con el desarrollo y equilibrio de la vida -en sentido extenso-, en este trabajo se exponen algunas bases filosóficas y jurídicas que sirven como elementos sustanciales para legitimar y promover que la Madre Tierra sea considerada como sujeto de derechos, con especial énfasis, en la dimensión jurídica, esto es, crear condiciones en el escenario o ambiente jurídico para que existan suficientes elementos en aras de defender y lograr una protección adecuada del ecosistema -medio ambienteHasta el momento en el campo jurídico únicamente se reconoce y protege el derecho a un medio ambiente sano y equilibrado -según la prescripción recogida en la Constitución Política de 1993 y esta situación se replica en la mayoría de textos constitucionales vigentes-, aquí se puede apreciar que el ser humano es la clave y el punto de articulación de toda la maquinaria jurídica, en especial, porque el humano es quien con exclusividad goza de derechos -es titular o sujeto de derechos-, en cambio, el medio ambiente es considerado como un medio o instrumento que sirve al ser humano, por tanto, carece de reconocimiento de derechos. Son embargo, con esta investigación se pudo encontrar fundamentos filosóficos y jurídicos para cambiar dicha realidad, esto es, la Madre Tierra transite de ser objeto de derecho a ser sujeto de derecho.

24 Revista Derecho-5 (2019)
Como lo hemos indicado, en este trabajo queda expuesto que existen fundamentos filosóficos y jurídicos que legitiman el reconocimiento de la Madre Tierra como sujeto de derechos. En tal sentido, ahora, sumariamente daremos cuenta de la forma en que se produce dicho reconocimiento desde las posturas filosóficas y jurídicas. Con relación a las posturas filosóficas, se considera la filosofía de la liberación y la filosofía andina, con respecto a la primera, se propone o sostiene que la filosofía debe ser pensada y ensayada desde la perspectiva de los oprimidos y excluidos, esto es, la periferia, a la vez, el método que utiliza es el analéctico que supone cuestionamiento a la universalidad de la filosofía tradicional -occidental- y propone el pensamiento situado para encontrarse con el otro o el distinto; con respecto al segundo-la filosofía andina, parte de la visión de los pueblos indígenas, en especial, pone énfasis en su cosmovisión y vivencia cotidiana de donde nace el respeto, cuidado de la vida y la naturaleza. Con referencia a las posturas jurídicas, se toman en cuenta el derecho indígena y el pluralismo jurídico, entonces, en relación al primero supone el conjunto de prácticas y concepciones de carácter consuetudinario que poseen los pueblos indígenas, tradicionalmente es anterior a la conquista o al Estado, a su vez, dichas prácticas incorporan el respeto de la naturaleza, y, con referencia al segundo -el pluralismo jurídico- se debe tener presente que es la 
expresión de diversos sistemas de resolución o administración de conflictos, la lógica bajo la que se conduce es distinta al derecho ordinario porque su fuente se encuentra en la cultura y las costumbres, donde subyace la noción de justicia indígena o comunitaria porque la solución de conflictos se produce considerando la perspectiva cultural.

En lo explicado desde la postura de la filosofía de la liberación y la filosofía andina, nítidamente, se puede establecer que parten de ideas sustanciales que consisten en exponer la sistemática exclusión y opresión que han sufrido las personas, en especial, las poblaciones indígenas y los pobres, dicha situación se presenció durante mucho años; y, concretamente, en relación a la naturaleza se considera que fue objeto de exclusión de la regulación jurídica como sujeto de derecho -fue una categoría excluida del derecho-, a su vez, la relación de armonía y equilibro entre ser humano y la Madre Tierra (sumakkawsay, suma qamaña, tekokavi) no fueron considerados, por consiguiente, desde la filosofía de la liberación y la filosofía andina se persigue cambiar dicha perspectiva. Por otro lado, sobre las posturas jurídicas se puede apreciar que el derecho indígena y el pluralismo jurídico introducen aspectos culturales y consuetudinarios que deben tomarse en cuenta para solucionar controversias jurídicas -enfoque cultural e intercultural en la resolución de conflictos-, por ende, la solu- ción jurídica -desde estas posturasfrente a los problemas ambientales debe producirse en clave intercultural, esto es, resolver las controversias enfocándose en por una cuestión de visión o cosmovisión cultural y consuetudinaria las poblaciones del ande -campesinos, indígenas, otros- mantienen una relación de equidad y equilibrio con la Madre Tierra, a su vez, es una entidad que goza de derechos -ocupa y representa algo especial-.

Con todo lo explicado, se puede intuir y considerar que existen razones para legitimar y reconocer que la Madre Tierra debe ser considerada como sujeto de derechos, en especial, dichas razones descansan en posturas filosóficas y jurídicas -los mismos que serán materia de desarrollo más adelante-. En ese orden, ahora, queda preguntarnos ¿qué significa e implica que la Madre Tierra posea derechos o sea considerado sujeto de derechos? Supone que la Madre Tierra tiene carácter sagrado, se reconoce su condición de ser viviente y tiene un estatus jurídico de sujeto de derecho (Molina, 2014). Entonces, el tránsito de una situación jurídica -en este caso de objeto de derecho a sujeto de derechos- implica la renovación jurídica, así como la adjudicación de nuevas herramientas para su tutela, a la vez, que existen nuevas estrategias más efectivas para promover su protección, en efecto, el reconocimiento de derechos a la naturaleza implica: (i) existencia de herra-

Revista Derecho - 5 (2019) 25 
mientas para su protección que son más eficaces, (ii) se reconoce a la Madre Tierra el valor intrínseco e independiente, esto es, no depende del ser humano, y, (iii) permite pensar en nuevos modelos de desarrollo que sea compatible con la Madre Tierra desde una visión del buen vivir.Y, concretamente, en términos técnico-jurídicos supone que al ser considerado como sujeto de derechos posee libertades, pretensiones, poderes e inmunidades a su favor (Barberis, 2008), al igual que el ser humano.

En suma, en este trabajo se da cuenta de los fundamentos filosóficos y jurídicos que existen para reconocer derechos a la Madre Tierra -sea considerada como titular de derechos-, por consiguiente, concretamente, desde los postulados de la filosofía de la liberación y la filosofía andina, así como el derecho indígena y el pluralismo jurídico se justifica que la Madre Tierra o pachamama goza de derechos al igual que el ser humano, además, se pone de relieve que el equilibrio y la armonía son las piezas esenciales para lograr la coexistencia de las diversas especies, incluida la humana. Es un hecho y dato incontrovertible que la tierra alberga diversas especies y que todos son iguales porque todas las formas de vida tienen las mismas expectativas de vida y desarrollo, por lo cual, denegar o restringir el reconocimiento de derechos a la Madre Tierra -que acoge a diversas formas de vida- es un acto de injusticia y desigualdad porque el ser humano frente a ella es igual en todas sus formas, por lo cual, debe recibir el mismo trato de los seres humanos. Además, con los resultados de la investigación ha quedado claro que se produce la mudanza del antropocentrismo hacia el biocentrismo porque desde las posturas filosóficas y jurídicas analizadas se considera con un elemento clave lograr el equilibrio y la coexistencia de todas las formas de vida existentes en este planeta porque es la casa común compartida con otras especies, a su vez, todos tienen derechos reconocidos, incluida, la Madre Tierra.

\section{MATERIALES Y MÉTODOS}

La metodología aplicada fue el análisis documental y hermenéutico, lo cual consistió en la recopilación de información teórica vinculada al problema que se investigó, a su vez, fue objeto de interpretación con la ayuda del análisis de las fuentes o referencias bibliográficas. Tuvo que restringirse el área de estudio a determinadas posturas filosóficas y jurídicas tales como son la filosofía de la liberación, filosofía andina, el derecho indígena y el pluralismo jurídico, se procedió de este modo porque el campo de estudio tanto de la filosofía y el derecho son extensos, por lo cual, tuvo que proceder la delimitación necesaria, además, las corrientes mencionadas son las más próximas a los propósitos de la investigación, en este caso, fundamentar el reconocimiento de 
derechos a la Madre Tierra. En relación a la técnica, se tuvo que utilizar la observación-directa que permitió tomar contacto con las fuentes bibliográficas y otros materiales necesarios para comprender los fundamentos que subyacen a cada postura filosófica y jurídica -especialmente, esta investigación se realizó con fuentes de carácter bibliográfico-.

El modo en que se ha sistematizado la información recopilada fue sobre la base de las unidades de análisis y se procedió del siguiente modo: (i) conceptualización y precisión de las posturas filosóficas y jurídicas que se investigan, (ii) clasificación de la información vinculada con las unidades de análisis posturas filosóficas y jurídicas-, (iii) organización de la información para reforzar la idea central de la investigación reconocimiento de derechos a la Madre Tierra-, y, (iv) determinación del impacto que tienen las posturas filosóficas y jurídicas en el reconocimiento de derechos a la Madre Tierra. Todo este proceso ha servido para postular y determinar que existen posturas filosóficas y jurídicas que legitiman y fundamentan el reconocimiento o adjudicación de derechos a la Madre Tierra.

\section{RESULTADOS Y DISCUSIÓN}

La discusión sobre el reconocimiento de la tierra como una entidad especial se remonta a la década de los
50 del siglo XX, ya que Aldo Leopold fue la primera persona en proponer que los individuos forman parte de una comunidad y la comunidad es un todo expresado en la tierra, por consiguiente, la actitud del ser humano como aquel agente capaz de transformar y modificar la naturaleza debía cambiar porque éste tiene la obligación de mostrar su respeto por otras especies y seres vivientes con los que comparte la tierra, concretamente, suponía cambiar el paradigma del ser humano como un conquistador de la tierra y, en vez de ello, se proponía que sea percibido como un miembro o especie más de la tierra. Esta teoría no fue muy acogida en su tiempo porque los esquemas de pensamiento todavía estaban cimentados en la idea de que el ser humano es el principal artífice que articula las relaciones sociales, a su vez, su deber era dominar la naturaleza. Posteriormente, James Lovelock planteó que la tierra es un organismo vivo en la que están integradas todas las partes, incluido el ser humano, por lo tanto, ello suponía que la tierra generaba una interrelación e interdependencia entre todas las especies que la habitan -ningún ser viviente era capaz de ser superior a la Gaia-. Finalmente, Arne Naess desde la ecología profunda postula que los seres humanos son elementos que forman parte de un sistema natural, por lo tanto, existe una íntima relación entre la naturaleza y el ser humano. 
En los últimos años el paradigma de reconocimiento de derechos fue variando porque los sujetos o entidades que no poseían derechos ahora son titulares de los mismos, tal como ha sucedido con la mujer o los animales -aunque en menor medida en este último caso-. La negación de derechos hacia la mujer fue una situación histórica muy dramática porque se producía la discriminación basada por cuestiones de sexo, sin embargo, fue modificado con el paso del tiempo. En relación a los derechos de la naturaleza o Madre Tierra sucede lo mismo, ya que por bastante años $-\mathrm{y}$ continúa en la actualidad- se le negó la categoría de sujeto de derechos y, por ende, no es titular de ningún derecho, a pesar de ello, hoy existen esfuerzos por considerar a la Madre Tierra como titular de derechos. La filosofía de la liberación y la filosofía andina, a su vez, el derecho indígena y el pluralismo jurídico son los pilares necesarios para justificar y fundamentar el reconocimiento de derechos a la Madre Tierra (o pachamama). Se acude a estas posturas porque la depredación y desgaste del medio ambiente están tornándose en insostenibles, por lo cual se requieren acciones concretas desde diversos áreas del conocimiento, ya que el problema ambiental es de carácter transversal y su impacto es general -todos los seres humanos resultan afectados-. En ese sentido, el reconocimiento de derechos a la naturaleza lo que busca es proteger y restaurar la afectación que se ha produ- cido en el medio ambiente, a su vez, es dotar de herramientas para su protección (Rivero, 2012).A este respecto, el presente artículo aborda los fundamentos de carácter filosófico y jurídico que hacen posible que la pachamama puede ser considerada como sujeto de derechos. En los próximos párrafos presentamos los argumentos que cada una de las posturas que pueden servir como fundamento y de esta forma legitimar a la Madre Tierra como sujeto de derechos.

\section{La filosofía de la liberación: la perife- ria y los excluidos se liberan de las cadenas del pensamiento impuesto}

La filosofía de la liberación es tomar posición así como ubicarse en el lugar de los excluidos y oprimidos para hacer filosofía desde esta perspectiva, concretamente, implica que la filosofía es de carácter militante porque busca visibilizar la agenda de los grupos o sectores de la población que permanecieron excluidos de forma sistemática. Es una búsqueda constante por liberar a quienes estuvieron oprimidos por la dinámica del sistema económico capitalista así como la colonización de ideas, por tanto, es un despertar en acción desde la perspectiva crítica. En ese sentido, se puede considerar que la filosofía representa un contra discurso porque la periferia, los oprimidos, los excluidos y todos aquellos quienes que no han sido capaces de iluminar y quedado sin palabras empiezan a proyectar cambios y 
transformaciones. Entonces, lo que pretende es producir un cambio radical con el apoyo y respaldo de la razón crítica, ello para garantizar que la hegemonía de una sociedad abierta no se imponga sobre los excluidos (Dussel, 2011).

El método que usa la filosofía de la liberación para comprender las opresiones y exclusiones es la analéctica que consiste en aceptar la ética de la interpelación del oprimido y la mediación de la praxis, concretamente, la praxis se traduce en la posibilidad de comprensión y esclarecimiento de la conciencia crítica. En tal sentido, la dialéctica permite la apertura hacia métodos que no solo son científicos y teóricos, sino que es un método que se enfoca a la ética y la praxis histórica. Así se entiende que es la afirmación de la exterioridad -no solo es negación del sistema- porque se realiza lo nuevo que consiste en el ejercicio de la libertad incondicionada, revolucionaria, innovadora (Dussel, 2011). Este método se enfoca en comprender el dolor y la exclusión -en especial, del otro- de las personas que no participan en el sistema y que están al margen porque se les ha sido negada su libertad y capacidad de innovación, por lo cual, es como un despertar en la búsqueda de la libertad.

La filosofía de la liberación exhibe una militancia activa a favor de los excluidos y oprimidos, en especial, de sectores populares, campesinos e indí- genas, a la vez, traslada su razonamiento sobre otras entidades o categorías que también sufrieron la exclusión, en este caso, la naturaleza o pachamama-medio donde se realiza la vida- es víctima del ascenso del sistema capitalista y extractivista. El extractivismo ha impuesto la idea de que la naturaleza debe ser conquistada y dominada para que el desarrollo del ser humano sea pleno y provechoso, sin embargo, las poblaciones campesinas e indígenas tienen una concepción distinta del desarrollo y progreso - que no supone la depredación de Madre Tierra-. Desde esta postura filosófica se busca reconocer y poner en conocimiento que, ahora, los excluidos tienen voz y representación, a su vez, pueden poner en la agenda pública sus concepciones sobre el desarrollo y la visión que tienen sobre la naturaleza, entonces, no resultará novedoso adjudicar el reconocimiento de derechos a la naturaleza porque es parte de la cosmovisión de las poblaciones indígenas y campesinas -situación que estuvo marginada y conminada en el olvido durante muchos años-, por lo tanto, se produce la liberación de la pachamama como objeto y se convierte en sujeto al cual se le reconocen derechos.

En suma, la filosofía de la liberación sobre la cuestión ambiental considera que la Madre Tierra, al igual que muchas personas, ha permanecido excluida y oprimida durante varios años, por esta razón, resulta pertinente cam-

Revista Derecho - 5 (2019) 29 
biar dicha situación. Concretamente, se puede apreciar que la naturaleza carece de reconocimiento jurídico como sujeto de derechos tal como se puede apreciar en el constitucionalismo contemporáneo, por ende, esta situación debe cambiar porque desde la visión de los excluidos - poblaciones indígenas y campesinas- la Madre Tierra es sujeto de derechos y guarda una relación especial con las personas porque es la fuente o medio de vida imprescindible para el desarrollo de las diversas especies. En ese sentido, la naturaleza como categoría excluida y sometida usa las herramientas de la filosofía de la liberación para cambiar su estatus -transitar el objeto a sujeto de derecho-, a la vez, romper las cadenas jurídicas impuestas a la pachamamade forma innecesaria.

\section{La filosofía andina: una aproxima- ción desde el buen vivir y la práctica}

En el presente trabajo nos enfocamos a una dimensión precisa de la filosofía andina que consiste en el buen vivir. Una categoría bastante trabajada en los últimos años es la noción de buen vivir o suma qamaña porque ella supone un marco axiológico que promueve la vida sostenible donde el ser humano sea comprendida dentro de un marco mucho más amplio, por ende, la idea de la centralidad y exclusividad del ser humano pierde fuerza porque también debe tener en cuenta que el mismo es parte de un espacio mucho más amplio, en este caso, la naturaleza. La regla ética del buen vivir que perdura en muchas poblaciones comunitarias exige respuestas creativas y eficaces para mantener la armonía, el equilibrio de la vida y la naturaleza y que sea capaz de parar la acelerada depredación de los recursos naturales y deterioro de la calidad de vida. El desarrollo más pertinente para el presente caso sobre la filosofía andina es la vinculación con el buen vivir que implica la armonía y equilibrio entre toda forma de vida. La filosofía andina tiene su traducción en el buen vivir

El buen vivir ha tomado impulso y mayor notoriedad cuando quedó reconocido en los principales instrumentos jurídicos, en este caso, la Constitución de Ecuador de 2008 y Bolivia 2009 estas constituciones forman parte del nuevo constitucionalismo porque combinan diversas visiones de los pueblos de América Latina así como Europa-recogen postulados vinculados al buen vivir. Este proceso de constitucionalización ha supuesto la armonización de las diversas tradiciones culturales y prácticas consuetudinarias, concretamente, se ha producido la convergencia entre la visión antropocéntrica y biocéntrica, a su vez, esto tuvo repercusiones en el modelo desarrollo que dichos países deben realizar -que sean más sostenibles y amigables con el medio ambiente-. En relación a la visión antropocéntrica se puede considerar que implica colocar al 
ser humano en el centro del universo, a la vez, todo lo que le rodea es sometido a ella. Con referencia al biocentrismo adjudica a la vida y existencia de los seres vivos valor intrínseco independientemente del ser humano, por consiguiente, la vida y su diversidad con el centro del universo (Pinto, Cerneiro, Da Silva, 2018). Y en el caso del buen vivir es una apuesta por la defensa de la vida porque proyecta una ética basada en la visión holística e integradora del ser humano, a su vez, está inmerso una comunidad terrenal donde toda forma de vida confluye y desarrolla (Boff, 2012; Naciones Unidas, 2010; Medici, 2010).

Concretamente en la Constitución de Ecuador se menciona que la naturaleza es titular de derechos -sujeto de derechos- por lo cual la misma tiene derecho a reproducirse, realizar la vida y regenerar sus ciclos vitales, por ende, cualquier persona puede exigir el cumplimiento de estos derechos a las autoridades competentes. Más adelante, el mismo texto constitucional indica que la restauración de la naturaleza supone la adopción de medidas de precaución y restricción de actividades que puedan suponer la extinción de especies, destrucción del ecosistema y la alteración permanente de los ciclos naturales [Artículos 71, 72 y 73 de la Constitución de Ecuador]. Y en la Constitución de Bolivia se menciona que la naturaleza será sujeto de aquellos derechos que le reconozca la carta constitucional [Artí- culo 10], adicionalmente, a través de la Ley que reconoce derechos de la Madre Tierra se le adjudicó el reconocimiento como sujeto de derecho, además no se debe olvidar que la carta constitucional contiene varias secciones o apartados donde explica sobre el buen vivir y el modelo de desarrollo compatible con la naturaleza, asimismo, coloca a la interculturalidad como un principio para sobre ella pueda producirse el reconocimiento de derechos a la Madre Tierra. Todo esto grafica el proceso de constitucionalización y el nuevo lugar que ocupa la naturaleza en dichos textos constitucionales.

En líneas generales, podemos explicar que todo lo estudiado por la filosofía y las ciencias sociales, sin embargo, fue objeto de constitucionalización porque en las Constitución de Ecuador y Bolivia se hacen referencia a la misma. El modo en que se ha instalado el buen vivir en dichas constituciones es para lograr una interpretación del texto constitucional de acuerdo a la realidad donde se desenvuelve. Al constituirse en un principio constitucional clave lo que sucede es que el buen vivir toma una posición central en la interpretación del texto, a la vez, plantea un esquema de comportamiento del Estado y la sociedad que tengan como objetivo el vivir bien (Dalmau, 2012, p. 719).

Finalmente, con todo esto ha quedado expuesto que la filosofía andina -

Revista Derecho - 5 (2019) 31 
a través del buen vivir- es una fuente importante para lograr el reconocimiento de derechos a la Madre Tierra, a la vez, se producen cambios en el horizonte del desarrollo de las naciones porque implica el tránsito de un modelo basado en el extractivismo hacia la un modelo equilibrados, también, el enfoque sobre la centralidad del ser humano cambia porque toda forma de vida y especies tienen las mismas expectativas y aspiraciones legítimas de vida. En estas condiciones, las cosas fueron mucho más asequibles para promover el reconocimiento de derechos. Cabe mencionar que el buen vivir implica límite a la actuación del Estado, a la vez, representa un conjunto de acciones que el poder público debe realizar a favor de las personas, concretamente, políticas públicas con enfoque desde esta orientación axiológica.En síntesis, el buen vivir ha significado la articulación social y política que tuvo como finalidad principal promover los aspectos más cruciales

\section{La filosofía y racionalidad andina}

El punto de inicio de la racionalidad occidental es que el ser humano es el fin de todo, esto es, la absolutidad de las cosas convergen en el ser humano. Esto se refleja en el campo económico, cultural, social y jurídico porque la dignidad del ser humano configura todas las relaciones políticas o de poder. En este caso, no tienen cabida otras formas de tratar y ver el mundo, es decir, nada puede funcionar distanciado de la idea de la dignidad humana. Frente a este modo de ver el mundo y las cosas, aparece la racionalidad andina que se fundamenta en que la centralidad y lo absoluto del ser humano pueden ser desplazados o ser cuestionados, ya que la cuestión económica, social, política o cultural no solo gira únicamente en base a las relaciones de los seres humanos. Así, en los próximos párrafos se abordará sobre las implicancias de la racionalidad andina.

En la racionalidad andina, en lugar de partir de la separación entre ser humano y naturaleza, se parte de la dualidad y la convergencia. Vida y cosmos son uno porque confluyen en el universo. En ese sentido, el hombre o persona del mundo andino actúa apegado a la dimensión telúrica y cósmica de la existencia, por esa razón, no se limita a explicar todo desde la configuración y complejidad del ser humano, sino que busca nuevas justificaciones considerando el espacio o entorno donde se desenvuelve o desarrolla la vida. Esto conlleva a que las relaciones culturales, sociales, económicas y jurídicas se desplazan o mueven en la dualidad y convergencia. En tal orden, la racionalidad o sabiduría andina se desarrolla bajo la cosmovisión, la costumbre y la vida del ser humano en constante contacto con la mística del universo y la madre tierra. La racionalidad andina de forma prístina puede ser observada cuando se pro- 
duce el reconocimiento de derechos a la naturaleza -situación ajena a la racionalidad occidental-, ya que el ser humano no es el único que posee u ostenta derechos, sino que la tierra y naturaleza también las tiene. Esta situación cambia radicalmente la forma de concebir y apreciar las cosas del mundo porque la naturaleza deja de ser considerada como un bien económico que sirve para satisfacer las necesidades del ser humano (hombre). Con esto queda claro que la racionalidad andina actúa en oposición a la racionalidad occidental, asimismo, presenta su propia forma de ver las cosas. Aquí no hay que olvidar que la sabiduría andina, también, dialoga con la ciencia occidental (conocimiento), ya que la sabiduría andina se basa en la observación, la práctica y la mirada holística de la vida, en cambio, la ciencia en sentido estricto usa el método científico, por tanto, podrían producirse puntos de encuentro y entrelazamiento (sin caer en la exclusión o incompatibilidad).

En tal sentido, desde la racionalidad andina se parte considerando a los pueblos originarios como colectivos que han practicado el conocimiento ancestral, el mismo que se expresa en costumbres y usos que fueron cambiando con el paso del tiempo, además, este tipo de conocimiento se transmite generación tras generación mediante fuentes orales (es el modo de conservación). En ese orden, los saberes que fueron brotando como parte de la racionalidad andina son ensayados de forma colectiva porque la práctica del conocimiento no se realiza de forma individual. Sobre ello, es importante establecer que la racionalidad andina maneja un enfoque holístico porque «permite ver las cosas enteras, en su totalidad, en su conjunto, en su complejidad, en los intereses de cada clase social» (Ponce, 2015, p. 73), por ende, hay involucramiento o relación constante entre «sujeto a sujeto, pues el uno está en el otro y el otro está en el uno» (Oviedo, 2016, p. 85). Así, los saberes y la narrativa de cada pueblo originario no se almacenan en un compilado de textos o libros, sino que se conserva en la memoria colectiva de sus miembros, además, siempre está siendo transmitido a través de la acción diaria de las personas. En tal sentido, el aprender desde la racionalidad andina está asociado a escuchar, observar a convivir y acompañar con cariño y gusto, de diversos modos y en variedad de circunstancias y ritmos de la vida campesina, quienes muestran sus saberes viviéndolos.

El enfoque occidental o colonizador de la racionalidad ha ido difuminándose en todas las experiencias posibles, es decir, se ha proyectado sobre la economía, la sociedad, el derecho, la política así sucesivamente, logrando cubrir casi todo. Esto lo que representó es que occidente acompañado con la razón privilegió los números, la materia, la razón, la lógica, la escritura, el

Revista Derecho - 5 (2019) 33 
hombre, lo abstracto, como superiores al sentimiento, la percepción, la ritualidad, la fiesta, la feminicidad, la naturaleza, por ende, el hombre era el único sujeto que quedaba y todo lo demás estaban sometidas hacia ella. Entonces, frente a esto como respuesta desde la racionalidad andina se promueve el ejercicio de la razón vinculado y apegado a los principios de la relacionalidad, complementariedad, reciprocidad con el todo. En tal orden, cobra importancia lo que dice J. Estermann cuando explica que:

«La realidad andina no tiene una concepción racionalista o empirista de las ciencias... sino que considera la 'ciencia' (el 'saber') como el conjunto de la sabiduría... colectiva acumulada y transmitida a través de las generaciones. Existe un 'saber' (yachay, yatina) del subconsciente colectivo, transmitido por procesos subterráneos de enseñanza de una generación a otra generación oral y actitudinal ('saber hacer'), mediante narraciones, cuentos, rituales, actos culticos y costumbres. Este 'saber' no es el resultado de un esfuerzo intelectual, sino el producto de una experiencia vivida amplia y meta-sensitiva...Los verbos quechua yachay y aymara yatiña no solo significan 'saber' y 'conocer' pero también 'experimentar'; un yachayniyoq o un yatiri es una persona 'experimentada', un 'sabio' en sentido vivencial. Como este tipo de 'experiencia' es un proceso transgeneracional y práctico (aprender haciendo), la 'ciencia andina' (no existe una palabra quechua o aymara propia) se fundamenta sobre todo en los argumentos de autoridad (el peso de los ancianos o yachaqkuna), de antigüedad (el peso de la tradición), de frecuencia (el peso de la costumbre) y de coherencia (el peso del orden)» (Chiroque, 2018, pp. 33 y 34).

La racionalidad andina actúa como un sustento especial para el derecho indígena porque incorpora elementos ancestrales y culturales para la experiencia jurídica. Lo más importante es que la dimensión jurídica, vista desde la racionalidad andina, exhibe compromiso con el dolor diario, toma en cuenta las experiencias de alegría, de esperanza, de pueblos históricamente olvidados, en consecuencia, el panorama jurídico se nutre de otras experiencias y saberes que le dan consistencia y legitimidad, en concreto, tenemos: (i) la cultura, (ii) la costumbre, (iii) la tradición ancestral, (iv) la vida colectiva, (v) la ritualidad, (vi) la relación entre hombre y naturaleza, entre otros. Así que el derecho indígena se configura con la presencia y confluencia de varios elementos que forman parte de la racionalidad andina.

En relación a la racionalidad andina y la ancestralidad, se ha indicado que las poblaciones indígenas, en especial, las comunidades campesinas del sector aimara «no son meros 
preservadores o repetidores de las tradiciones de sus antepasados; al mismo tiempo que dan valor a lo ancestral también lo interpretan y lo transforman o reformulan en el contexto de la vida presente» (Valencia, 1998, p.37). En ese sentido, los aportes y avances en el derecho indígena se valoran en esta dimensión, esto es, la revaloración y renovación de lo tradicional o ancestral. Es constante la interpelación de la razón o racionalidad occidental porque la cosmovisión, la forma de vida, la práctica de conocimiento cultural, entre otros, de las poblaciones indígenas y campesinas son distintas. Según la racionalidad occidental la razón se sobrepone a las emociones y los sentimientos, en cambio, la racionalidad andina propugna que las emociones y los sentimientos son esenciales para la existencia.

Finalmente, en el marco de la racionalidad andina, los sistemas normativos y jurídicos son construido teniendo como punto de referencia al mundo y el ser humano, es decir, es un derecho que se establece a la medida de los hombres y la pachamama. Ello es así porque no están separados o distanciados según la filosofía andina. Sucede lo contrario en la filosofía occidental donde el derecho se elabora tanto para las personas así como el entorno geográfico porque no existe la unidad y confluencia entre humanidad-mundo (tierra). En contraposición a este esquema o manera de concebir el derecho se opone el derecho indígena, el mismo que plantea la recuperación de las experiencias vivas de las comunidades campesinas e indígenas, asimismo, el derecho se legitima y se construye desde abajo para volverse en transformador y emancipador.

\section{El derecho indígena: derecho en pro- ceso de construcción y visibilización}

Es posible ubicar las raíces del derecho indígena junto con el origen de las comunidades campesinas y amazónicas (existentes anteriores a la colonización y la conquista). Ello resulta así porque el derecho avistado desde la visión andina es esencialmente espontáneo y responde al sentido común de sus miembros, esto es, un derecho que nace como sentimiento y opera sometido a los principios y valores -prácticas cotidianas- en las que se ven envueltas cada comunidad o población indígena. Como correlato a la aparición o génesis de un grupo social o humano, en este caso comunidad campesina o indígena, subyace la noción de derecho, es decir, un esquema que sirve para sancionar conductas agresivas y ofensivas contra los integrantes del grupo, además, es un medio para garantizar la convivencia ${ }^{1}$.

\footnotetext{
Con estos elementos, básicamente, se asocian al derecho indígena, sin embargo, existen más aspectos a ser tratados, los mismos que se desarrollarán más adelante porque operan como fundamentos jurídicos o ejes articuladores que sirven para reforzar este derecho.
} 
Es muy probable que las primeras sociedades de AbyaYala no hayan sido conscientes de la existencia del derecho $^{2}$, sin embargo, siempre estuvieron practicándola, ya que es imposible desligar el derecho de la existencia de una organización social; es evidente que esta forma jurídica no era sofisticada tal como la conocemos hoy, pero servía para los fines que el colectivo deseaba alcanzar: (i) convivencia pacífica a través de la creación de normas de conducta claras, y, (ii) solución de conflictos.

Este derecho tiene larga data en el Abya Yala porque las poblaciones (comunidades, grupos, entre otros) de este continente han sabido organizarse y promover prácticas jurídicas para garantizar la convivencia pacífica y ordenada, no solo ello, sino que también han creado un marco jurídico para resolver conflictos de manera legítima, es decir, aceptada por todos sus miembros. A ello, también, hay que añadir que la filosofía que la inspira consiste en la armonía y la consecución del buen vivir, es más,en ello se apoya toda la dinámica jurídica porque el sistema de usos y valores practicados en este continente, en especial, por las comunidades campesinas e indígenas son el sustrato necesario para impulsar el sistema de reglas -en sentido amplio- que representa el derecho. Es así que el proyecto filosófico y jurídico tiene como esquema el buen vivir porque representa el «pilar axiológico y marco de derechos y obligaciones en una sociedad donde el proceso vital del ser humano cobra sentido integral tanto en su construcción como persona como en su contribución con el mundo» (Martínez, 2013, p. 718; Bonilla, 2015; Correas, 2010). Esto significa que es una compresión integral de la persona donde la persona y el medio donde habita son consustanciales, por esa razón, el derecho indígena no puede prescindir de la noción de naturaleza, pachamama o madre tierra.

La concepción que tienen los pueblos indígenas sobre el derecho, habitualmente, se apoya en sus usos y costumbres, en efecto, la forma de comprender la dimensión jurídica está moldeada por su cosmovisión y la profunda conexión que mantiene con todo lo que existe en la tierra (aire, agua, cielo, animales, plantas, otros). En tal sentido, el derecho es un sistema de reglas y pautas de comportamiento consuetudinarios porque responde a un esquema de visión del mundo y el cosmos, en ese sentido, lo más importante es que mediante el derecho los miembros logren convivir en paz y armonía. Este tipo de derecho por muchos años fue relegado de la esfera jurídica tradicional (occidental, europeo) porque no eran reglas válidas. En tal sentido, el fenómeno jurídico solo po-

Esto también sucedió con las sociedades europeas o norteamericanas porque el derecho fue una ficción que se va creando con el paso del tiempo, pero en el momento inicial de la vida no existe como tal y tampoco se tiene conciencia de ello, por ese motivo, el mismo fenómeno se replica a nivel global.

36 Revista Derecho-5 (2019) 
día ser válido si era producido en las escuelas de derechos de universidad de Europa o Norteamérica, por esa razón, tardó mucho en aflorar el derecho indígena dentro de la práctica jurídica contemporánea. A pesar que sus orígenes son bastante extendidos en la experiencia latinoamericana.

El derecho indígena en las últimas décadas está en proceso de construcción y consolidación porque empieza a ser revalorada y cada vez va ocupando una posición importante en los sistemas políticos, económicos, culturales, sociales y jurídicos, al menos, en gran parte de América Latina y en algunas partes del mundo (en especial, aquellos lugares donde la diversidad cultural fue escondida). En el contexto latinoamericano este proceso de puesta en valoración implicó: (i) reconocimiento de la diversidad cultural en los textos constitucionales a partir de la década de los 80, (ii) incremento de estudios que dan cuenta sobre la diversidad cultural, es decir, sus posibilidades y problemáticas, (iii) la apertura de la sociedad hacia la dimensión cultural, esto es, el sentido de convivencia con la diversidad cultural, (iv) la construcción de la sociedad desde la perspectiva plural e intercultural, (v) los sistemas jurídicos ponen más atención y especial cuidado al momento de solucionar conflictos vinculados con cuestiones de carácter cultural, entre otros. Estos son algunos de los factores que propiciando el fortalecimiento y desa- rrollo del derecho indígena en América Latina.

Finalmente, una conceptualización liminar del derecho indígena consiste en que es una práctica jurídica de carácter comunitario u originario que sirve para solucionar conflictos de forma pacífica, a su vez, la filosofía que la inspira está cimentada en el buen vivir o suma qamaña porque busca la integridad de las relaciones entre las personas y la pachamama. Es un derecho restaurador y reparador de los vínculos comunales, esto es, garantizar que los lazos afectivos, familiares, personales y colectivos sean preservados. Además, la lógica a la que responde es el sentido común y la tradición (costumbre, usos, entre otros), quizás esa sea la razón por la que el binomio ser humano-naturaleza son indesligables, ya que es imposible pensar la organización social, política y cultural prescindiendo de la naturaleza, en el mismo sentido, la administración de justicia no puede ser solo de hombres, sino que debe incorporar el elemento telúrico y sagrado que emana de la naturaleza.

\section{El pluralismo jurídico: construcción plural y diversa de las experiencias jurídicas}

Es menester indicar que el pluralismo jurídico es una noción de reciente data, pero que ha tenido mucho éxito y fue bastante desarrollado en el pensa-

Revista Derecho - 5 (2019) 37 
miento jurídico contemporáneo. La tesis central del pluralismo jurídico es promover el diálogo y la conexión entre las distintas experiencias jurídicas que existen en un determinado país, concretamente, la interrelación entre los sistemas de solución de conflictos. Y es que las sociedades plurales y diversas como la nuestra, normalmente, las manifestaciones en diversos campos también se producen de acuerdo a dicha diversidad, por tanto, el asunto jurídico no es una ajena u óbice a ello. Todas las culturas poseen formas o maneras de experimentar o concebir lo jurídico $-\mathrm{o}$ tienen un sistema propio de protección de derechos y resolución de conflictos-. En tal sentido, el pluralismo jurídico trata de rescatar y poner de relieve la diversidad de formas de componer o solucionar los conflictos que existen dentro de cada sociedad o grupo cultural, en efecto, la heterogeneidad promueve que el modo en que debe entenderse y lidiar con un conflicto no sea unilateral sino que sea diverso.

Según el pluralismo jurídico el centro de producción del derecho no se limita únicamente al legislador, sino que también tiene presencia otros actores como son: (i) las comunidades campesinas, (ii) los grupos indígenas, otros, ya que todo tipo de sociedad posee u ostenta un derecho propio, esto es, un sistema de reglas concreto de acuerdo a sus intereses sociales, convicciones axiológicas, prácticas culturales, entre otros. Entonces, la consolidación del pluralismo jurídico también pasa por mejorar el acceso a la justicia de la población, esto es, administrar justicia tomando en cuenta elementos como la lengua, las costumbres y prácticas culturales que son propias de una comunidad que son distintas de los cánones y reglas que se practican en el derecho ordinario-. En la misma línea, el pluralismo jurídico implica efectuar las siguientes acciones desde el Estado: (i) promover entre la justicia comunal y el Poder Judicial una relación que respete la interculturalidad y regulará las competencias, atribuciones y limitaciones de aquélla, (iii) consolidar la regulación de la justicia de paz y la elección popular de los jueces de paz. Con esto queda demostrado que la justicia comunal o el derecho indígena no está condicionado al derecho oficial o estatal, sino que tiene autonomía de funciones y competencias, en tal sentido, los órganos del Estado tienen que cooperar e interactuar (interrelación entre derecho indígena y derecho estatal).

¿Cómo es que mediante el pluralismo jurídico se puede lograr el reconocimiento de derechos a la Madre Tierra? Es una interrogante difícil de responder, sin embargo, la clave de la respuesta radica en comprender que el pluralismo jurídico tiene como eje central de su legitimación la cultura y las prácticas consuetudinarias de las poblaciones indígenas o campesinas, a su vez, la 
solución de las controversias se produce respetando el elemento cultural. En ese sentido, la visión y comprensión del derecho, según el pluralismo jurídico, son distintos porque la fuente de legitimación de las normas o reglas son las pautas culturales así como los usos de cada comunidad o entorno cultural, ya que la validación del contenido del derecho en el pluralismo jurídico se basa en la identidad entre las prácticas culturales y el respeto de los mismos por sus miembros.Entonces, en la práctica cultural de un determinado grupo existen diversas nociones sobre la justicia, los valores, el Estado, entre otros, lo mismo sucede con la naturaleza, esto es, cada grupo cultural tiene una concepción sobre la naturaleza así como su importancia, por ende, no resulta nada novedoso que le reconozca derechos a la misma porque es parte de su visión y tradición, por lo cual, el derecho lo que debe hacer es reconocer y establecer como un elemento central dicha noción.

Finalmente, el pluralismo jurídico es una postura que fundamenta el reconocimiento de derechos de la naturaleza porque el marco o canon interpretativo que utiliza tiene como base la diversidad cultural, esto es, promueve la comprensión más amplia y sensible de la realidad jurídica, en especial, vinculado a la diversidad cultural. En este caso, el pluralismo jurídico propone que en zonas o lugares donde existan fricciones o contradicciones entre el derecho ordinario -basado en reglas jurídicas producidas por el legislador- y el derecho consuetudinario -derecho practicado y producido por las comunidades indígenas o campesinas- debe darse preferencia al segundo para que no se produzcan fraccionamientos o rupturas innecesarias. Ello resulta así porque se entiende que el derecho producido y practicado en las comunidades es mucho más sensible y contextualizado a la realidad, a su vez, encaja con la cosmovisión y la perspectiva cultural.Al respecto, concretamente, en las poblaciones indígenas y campesinas de América Latina existe la noción de que la naturaleza posee derechos, por ende, la solución de un problema o controversia en materia ambiental debe considerar dicho aspecto porque es parte de su práctica y tradición cultural.

\section{Balance general: la utilidad de las posturas filosóficas y jurídicas en el reconocimiento de los derechos de la Madre Tierra}

En esta parte podemos empezar efectuando la siguiente interrogante ¿cuál es la utilidad de los fundamentos que ofrecen las posturas tanto filosóficas así como jurídicas para el reconocimiento de derechos a la Madre Tierra? Esta interrogante de carácter funcionalista apunta a encontrar las razones y repercusiones prácticas del reconocimiento de derechos a la Madre Tierra, entonces, concretamente pode-

Revista Derecho - 5 (2019) 39 
mos desbrozar las siguientes respuestas: (i) los fundamentos de las posturas filosóficas y jurídicas sirven para modificar el pensamiento y razonamiento de las personas en relación a la naturaleza, esto es, cambiar la perspectiva de que únicamente piensen que es un objeto o entidad inanimada, sino que debe considerarse como sujeto de goza del reconocimiento de derechos, (ii) las modificaciones legislativas que se efectúen en relación a cuestiones de carácter ambiental debe considerar que la naturaleza es sujeto de derechos y la regulación debe promover ello, y, (iii) la interpretación realizada por los operadores jurídicos en especial los jueces- al momento de solucionar conflictos relacionados con el medio ambiente, necesariamente, deben considerar que la Madre Tierra es sujeto de derechos. Estos son las principales repercusiones, sin embargo, existen muchos más.

Hay que centrarse en que las posturas filosóficas y jurídicas que fundamentan el reconocimiento de derechos a la Madre Tierra parten de la exclusión y la situación de desventaja en la que se han visto sumidas las personas en el continente Latinoamericano -concretamente, los indígenas y campesinos-,esta misma situación se ha producido en relación a la concepción de la naturaleza, esto es, la Madre Tierra ha quedado desprovisto de derechos porque se consideraba un objeto, sin embargo, dicho escenario fue tornándose distinta con el paso del tiempo, en especial, influenciado por el pensamiento indígena se pasó a concebir a la naturaleza como sujeto de derechos, tal como se ha podido establecer en este trabajo. Por otro lado, también debe tenerse presente que el planeta viene atravesando por una situación de crisis ambiental, por lo cual, detener la creciente depredación ambiental es urgente, siendo necesario establecer nuevos esquemas de pensamiento que resulten ser más compatibles y coherentes con la conservación así como equilibrio de la naturaleza, y, de alguna norma forma, con las posturas aquí expuestas se logran tal finalidad -por lo menos tiene un potencial significativo en términos jurídicos-.

En suma, de todo lo explicado se puede desprender que la utilidad de las posturas filosóficas y jurídicas radica en: (i) influir al momento de cambiar la legislación vigente, especialmente, para admitir que la naturaleza posee derechos, y, (ii) establecer que el esquema de razonamiento de los operadores jurídicos, en especial, cuando tengan que resolver casos o controversias vinculadas con la protección del medio ambiente debe generarse un criterio interpretativo que se direccione hacia el reconocimiento de derechos de la naturaleza o Madre Tierra, a su vez, tomar en cuenta que la filosofía de la liberación, la filosofía andina, el pluralismo jurídico y el derecho indígena poseen 
fundamentos válidos para adjudicar derechos a la naturaleza.

\section{CONCLUSIONES}

Las posturas filosóficas que promueven elreconocimiento, adjudicación y fundamentación de la Madre Tierra (naturaleza o pachamama) como sujeto de derechos -sea titular de derechosson la filosofía de la liberación y la filosofía andina.La primera postura filosófica ofrece unacercamiento a la cuestión ambiental desde la experiencia de los pobres, los excluidos, los oprimidos y la periferia, a su vez, la naturalezao Madre Tierra es una categoría excluida del marco jurídico, por consiguiente, desde esta postura filosófica se propone el reconocimiento de la Madre Tierra en los sistemas contemporáneos como sujeto de derechos -la adjudicación de derechos supone salir de la exclusión y la invisibilización-.En el caso de la segunda postura, la intención es revalorizar así comoponer en práctica las tradiciones culturales de las poblaciones indígenas, en especial, comprender la relación de equilibrio y simetría que se produce entre el ser humano y la pachamama, por lo tanto, desde aquí se propone que la naturaleza también sufre porque experimenta dolor cuando el ser humano altera sus ciclos de vida, entonces, para evitar y mitigar dicha situación se debe promover
En relación a las teorías -o posturas- jurídicas, principalmente, encontramos: (i) el pluralismo jurídico: supone administrar justicia desde la perspectiva de la diversidad -existencia de varios mecanismos para solucionar un problema-, en especial, se introduce la noción de la diversidad cultural y social como un elemento central al momento de resolver un conflicto -en este punto, se advierte queal momento de resolver un asunto vinculado con la protección del medio ambiente pueden usarse diversos argumentos que ofrece el pluralismo jurídico para defender la posición de que la naturaleza posee derechos-; (ii) el derecho indígena: es una concepción del derecho que parte de la costumbre y la tradición cultural de un pueblo, en especial, con relación a la resolución de conflictos implicaque la construcción del conocimiento jurídico no debe obviar o prescindir de la práctica cultural o consuetudinariade las poblaciones indígenas o campesinas-es común observar que en algunos lugares el respeto y contemplación a la naturaleza es un componente muy fuerte, por lo tanto, en muchos casos se le reconoce derechos.

El elenco de posturas filosóficas y jurídicas expuestas apuestan por el reconocimiento de la Madre Tierra como sujeto de derechos, en razón a que considera a la pachamama como fuente de vida -garantiza la existencia de varias especies, incluida, la humana-, adicionalmente, el ser humano no es el

Revista Derecho - 5 (2019) 41 
centro del cosmos, sino que existe convivencia y relación recíproca con otras especies, por consiguiente, el hombre y la Madre Tierra deben permanecer en armonía y equilibrio. En ese orden, sobre la base de las posturas filosóficas y jurídicas expuestas es posible justificar que la naturaleza -o Madre Tierra- sea reconocida como titular de derechos, lo cual implicaque posee autonomía respecto de los seres humanos, a la vez, ella misma alberga otros tipos de especies distintas al humano.Además, los usos que pueden tener los argumentos y razones ofrecidas en este trabajo son diversos: (i) pueden ser utilizadas por los operadores jurídicos como argumentos válidos para promover el reconocimiento de derechos a la naturaleza-en especial los jueces-, y, (ii) pueden servir como fuentes de argumentación para elaborar propuestas legislativas o reforma constitucional donde se consigne el reconocimiento de derechos a la Madre Tierra.

\section{REFERENCIAS BIBLIOGRÁFICAS}

Barberis, M. (2008). Ética para juristas. Madrid: Editorial Trotta.

Boff, L. (2012). ¿Vivir mejor o «el buen vivir»? Recuperado de $\mathrm{h} \quad \mathrm{t} \quad \mathrm{t} \quad \mathrm{p}: / /$ servicioskoinonia.org/ a genda/a r c hivo / obra.php?ncodigo $=757[\mathrm{Vi}$ - sitado el 4 de agosto de 2019 a las 10:15 am]

Bonilla, D. (Comp.) (2015). Geopolitica del conocimiento jurídico. Bogotá: Siglo del Hombre Editores y Universidad de los Andes.

Chiroque, S. (2018). Manual para el desarrollo de competencias en investigación formativa. Lima: Tarea asociación gráfica educativa.

Correas, O. (2010). Teoría del derecho y antropología jurídica. Un diálogo inconcluso. México: Ediciones Coyoacán.

Dussel, E. (2011). Filosofía de la liberación. México: Fondo de Cultura Económica.

Gitlitz, J. (2013). Administrando justicia al margen del Estado. Las Rondas Campesinas de Cajamarca. Lima: Instituto de Estudios Peruanos.

Herrera Flores, J. (2008). «La complejidad de los derechos humanos. Bases teóricas para una $\mathrm{r}$ e d e f i n i c i ó n contextualizada». Revista Internacional de Direito e Cidadania, $\mathrm{n}^{\circ}$ 1, p. 103 135.

42 Revista Derecho - 5 (2019) 
Martínez Dalmau, R. (2013). «Vivir bien e innovación en el nuevo constitucionalismo: la Constitución ecuatoriana de 2008», en XV Encuentro de Latinoamericanistas Espanoles. Madrid, pp. $708-722$.

Medici, A. (2010). «Teoría constitucional y giro decolonial: narrativas y simbolismo de la Constitución. Reflexiones a propósito de la experiencia de Bolivia y Ecuador», $G a$ ceta Constitucional, $\mathrm{n}^{\circ}$ 48, pp. $329-348$.

Molina Roa, J. (2014). Derecho de la naturaleza. Historia y tendencias actuales. Bogotá: Universidad Externado de Colombia.

Naciones Unidas (2010). Estudio sobre la necesidad de reconocer y respetar los derechos de la Madre Tierra. Nueva York, 19 a 30 de abril de 2010. Foro permanente para las cuestiones indígenas.

Pásara, L. (1978). Reforma agraria: derecho y conflicto. Lima: Instituto de Estudios Peruanos.

Pinto, I. et. al., (2018). «La naturaleza como sujeto de derechos: análisis bioético de las Constituciones de Ecuador y Bolivia». Revista Latinoamericana de Bioética, 18 (1). 155 - 171. Doi: https:// doi.org/10.18359/ rlbi.3030

Rivero, O. (2012). Crisis global. Lima: Universidad Inca Garcilaso de la Vega.

Ugarteche, O. (1999). La arqueología de la moderniadad. Perú entre la globalización y la exclusión. Lima: DESCO.

Valencia, N. (1998) en su texto la Pachamama: Revelación del Dios Creador dice sobre el punto decía «Los aimaras».

Revista Derecho - 5 (2019) 43 
44 Revista Derecho-5 (2019) 